\title{
Analysis of Multi-Criteria Evaluation Method of Landfill Site Selection for Municipal Solid Waste Management
}

\author{
Habiba Ibrahim Mohammed ${ }^{1 *}$, Zulkepli Majid ${ }^{1}$, Norhakim Bin Yusof ${ }^{1}$, and Yamusa Bello \\ Yamusa $^{2}$ \\ ${ }^{1}$ Faculty of Geoinformation and Real Estate, Universiti Teknologi Malaysia, 81310 Skudai, Johor, \\ Malaysia \\ ${ }^{2}$ Department of Civil Engineering, Nuhu Bamalli Polytechnic, 810001 Zaria, Nigeria
}

\begin{abstract}
Landfilling remains the most common systematic technique of solid waste disposal in most of the developed and developing countries. Finding a suitable site for landfill is a very challenging task. Landfill site selection process aims to provide suitable areas that will protect the environment and public health from pollution and hazards. Therefore, various factors such as environmental, physical, socio-economic, and geological criteria must be considered before siting any landfill. This makes the site selection process vigorous and tedious because it involves the processing of large amount of spatial data, rules and regulations from different agencies and also policy from decision makers. This allows the incorporation of conflicting objectives and decision maker preferences into spatial decision models. This paper particularly analyzes the multi-criteria evaluation (MCE) method of landfill site selection for solid waste management by means of literature reviews and surveys. The study will help the decision makers and waste management authorities to choose the most effective method when considering landfill site selection.
\end{abstract}

\section{Introduction}

Identifying a suitable site for the disposal of municipal solid waste is a very demanding task requiring a lot hard work for the municipality. There are different factors and criteria that needs to be given careful consideration before siting a landfill [1]. The selection process is very demanding because of its effects on the economy, environments and health are numerous. The developing countries are facing difficulty in waste management due to the population growth, urban migration, inappropriate planning, and lack of sufficient resources [2]. Getting rid of unwanted materials through landfills is an unavoidable event in solid waste management practice.

Waste disposal of residual proportion produced on land is an inevitable aspect of solid waste management even if all the measures of reduction, reuse and recycling are being employed in the environment. The sanitary landfill has become the most well-known and

* Corresponding author: mydearhabiba@yahoo.com 
popular method of solid waste disposal in many developed and developing countries [3]. Furthermore, proper landfill site selection is an essential step in solid waste disposal practice and towards ensuring sustainable environment, good health, and quality of life for the future. To avoid the undesirable long-term effects of the landfill to the environment, it is important to implement a proper landfill siting. Therefore, careful consideration of siting criteria (constraints and regulations) set up by environmental agencies or local authorities should be employed for a suitable landfill site [4].

One of the most important tool used in land use suitability analysis recently is the Geographical information systems (GIS), also this same tool can be applied for landfill siting [5]. The benefit of the GIS-based method in site selection study include time and energy saving, cost reduction as well as provision of digital data for the site monitoring for long-term [6]. The reason is because GIS has the storage capacity, easy management and maintenance of the analyzed geographical data, and it is well designed for spatial and descriptive dependency data [7]. The combination of GIS features and multi criteria decision analysis (MCDA) methods gives rise to a convenient method for spatial multicriteria decision analysis (SMCDA) for optimal landfill siting. This integration method of both techniques has been broadly used to a great extent in different landfill site selection studies [5]. In landfill siting decisions, various factors have to be incorporated and for this type of study, and geographic information systems (GIS) are the best ideal tools to carry out such study because of its ability in spatial data management especially in large volume [8]. The GIS is very important in siting process because it efficiently display and manage data from different type of sources, also, the cost and time of the siting process is reduced $[9,10]$. Recently, over the past few years GIS developed into a very useful strong tool that can perform different type of analysis using spatial data. This is $\mathrm{s}$ also due to the technological advancement in computing technology and the availability of various kind of spatial data. Environmental models and GIS function with a broad range of related geospatial data used for a variety of applications and spatial analysis at different levels. Data evaluation and organization into a meaningful form produces a reliable information, which then gives rise to suitable analysis and modeling [11].

Literature review regarding landfill site selection and its methodology was conducted from various studies in different part of the world. This review paper specifically considers in detail the Geospatial based strategies of landfill site selection for municipal solid waste particularly the Multi-Criteria Evaluation techniques (MCE) by means of related literature and surveys. The study will help the decision makers and waste management authorities to know which method is to be considered most effective.

\section{Literature Review Related to Landfill Siting}

A lot of literature related to landfill site suitability analysis has been conducted over the years with the integration of GIS and MCDA. These methodologies have been widely used by many researchers in different countries in order to achieve suitable landfill site for waste disposal e.g. $[1,3,12]$. Fig. 1 describes the process and steps to be taken when siting a new landfill considering environmental, socio-economic, design, areas availability and technical criteria. 


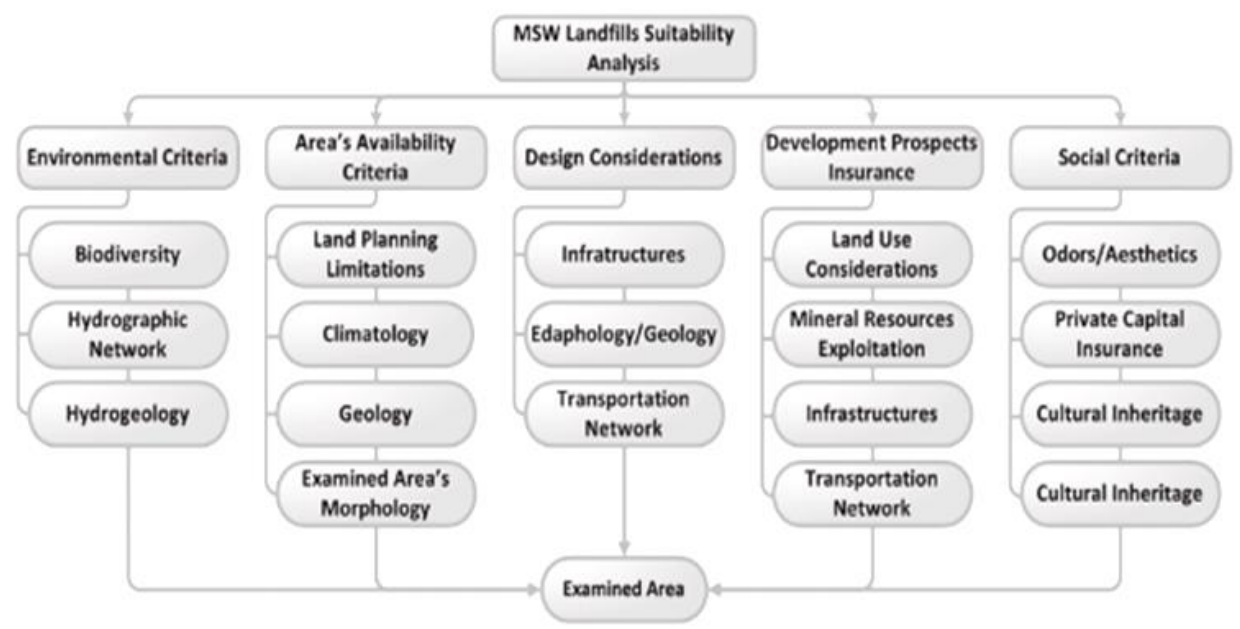

Fig. 1. Landfill site selection process [13].

Furthermore, several studies discussed the integration of GIS and multi-criteria decision analysis and its efficiency in solving the site selection problems. Landfill site selection process involves multiple criteria and conflicting objectives in decision- making therefore, it considers not only scientific analysis and data-mining, but also political factors and public acceptance [14]. This is because the site selection for landfill is very difficult as it requires large number of criteria both economic, environmental, social, political, and technical as shown in Fig. 1. In order to identify a landfill site, an evaluation process is required for optimal and best site selection [15]. This site selection process is increasingly becoming more complex and difficult, and it must be in accordance with rules and regulations governs by the authority [16].

\section{Methods of Multi Criteria Decision Analysis}

Multi-Criteria Decision-Making method support decision-making involved with conflicting objectives and multiple criteria [17]. The MCDA methods assist the decision makers in coming out with the best solutions or alternatives [18]. The MCDM is able to deal with large number of criteria, which makes it to be considered as an efficient method for decision support tool. Fig. 2 shows the structure of framework for spatial multicriteria decision analysis. 


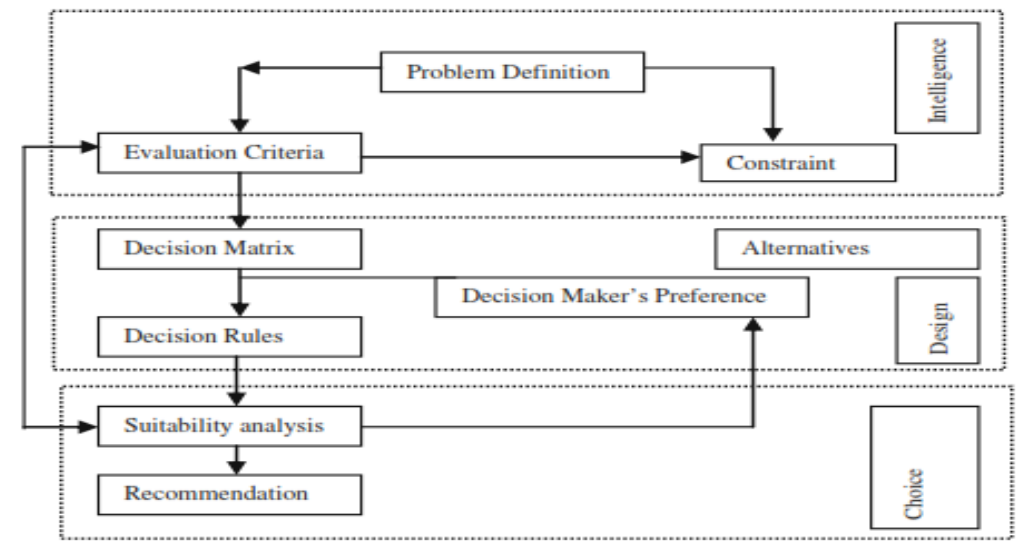

Fig. 2. Structure of spatial multi-criteria decision analysis [19].

\subsection{Fuzzy Logic}

This method was first innovated by Zadeh (1965) to identify and describe the uncertainties related with criteria and sub-criteria assessment. The selection criteria are weighted to represent the importance and contribution of each factor [19]. With Fuzzy Logic, criteria standardization is very accurate with the use of fuzzy membership function.

\subsection{Weighted Linear Combination}

This method is applied when dealing with Multi Attribute Decision Making (MADM). It is an analytical technique, which is used when there is more than one attribute to be considered based on the content of weighting average. The attributes are known as criteria and each of these criteria are assigned value (weight) based on its importance where the favorable outweigh the unfavorable. The outcome of it is multi-attribute features with a standardized score allocated to each. From the scores, the areas with higher scores indicate the level of adequacy. Example of this weighted linear combination method include land suitability analysis [20]. One of the most commonly used MCE methods in GIS-based studies is Weighted Linear Combination especially in land suitability analysis, site selection and evaluation analysis [21]. This method can be performed by GIS and overlapping capacities of this system. Use of this method is practical in both raster and vector format [22].

\subsection{Analytic Hierarchy Process (AHP)}

The most popular and most commonly used MCDA method is Analytic Hierarchy Process (AHP) which was introduced and established by Saaty [23]. It is a decision-making tool used in solving multiple criteria problems because of its ability in the determination of relative weight of multiple criteria, which are expressed in numerical order of 1 to 9 . Pair wise comparison method is carried out among the criteria through the scores and weights assigned to each criterion [24].

AHP is complicated when there is large number of criteria to be the considered in the decision-making process. Saaty [25] explain the scale values and their definition as shown in Table 1. 
Table 1. Pair wise comparison scale.

\begin{tabular}{|c|l|}
\hline $\begin{array}{c}\text { Intensity of } \\
\text { importance }\end{array}$ & \multicolumn{1}{c|}{ Definition } \\
\hline 1 & Extremely less important \\
\hline 2 & Very strongly less important \\
\hline 3 & Strongly less important \\
\hline 4 & Moderately less important \\
\hline 5 & Equally important \\
\hline 6 & Moderate important \\
\hline 7 & Strongly important \\
\hline 8 & Demonstrate important \\
\hline 9 & Extreme important \\
\hline
\end{tabular}

\subsection{Ordered Weighted Averaging (OWA)}

Ordered weighted average is a recent MCDA integration technique which is used to rank criteria. OWA is able to identify specific uncertainties related to criteria ranking. There is some trade-off among the criteria which are controlled by the ordered weights thus, giving rise to the best output in planning process [26]. It is also flexible to use because the level of importance of criteria can be changed based on expert decision [27]. Table 2 shows some outline of the advantages and disadvantages of the MCDA methods.

\section{Multi-Criteria Decision Analysis using GIS}

Presently, integration of GIS and MCDA plays an important role in selecting site for landfill. GIS-based approach has the capability of providing the spatial data in digital format which can be used for long term monitoring of the site, also it is able to save time and cost in the landfill siting process [10]. Some researchers [28] provided a method describing the process for municipal landfill sites identification in urban areas in Sierra Leone using a multi-criteria and GIS approach. The weighted linear combination (WLC) and ordered weighted averaging (OWA) was used as the MCE technique. From their studies, it was revealed that $83 \%$ of the study areas were unsuitable for the landfill siting.

A study conducted by [12] applied both GIS-based and multi-criteria evaluation approach for characterizing and assessing potential favorable landfill sites in the Polog Region in Macedonia. The environmental and economic factors were considered as multicriteria decision framework, which were standardized by fuzzy membership functions after which they were integrated with analytical hierarchy process (AHP) and ordered weighted average (OWA) techniques. The AHP methodology was used to evaluate the importance of criteria and generates the global weights, which were used in conjunction with the local weights in OWA procedure for producing the decision alternatives.

Furthermore, [29] developed an integrated fuzzy logic and analytic network process (FANP) with the aim of locating a suitable site for disposing municipal solid wastes generated in Kahak Town, Qom, Iran. Their findings shows that the application of fuzzy logic and analytical neural process can be implemented in landfill site selection in similar study areas.

In addition, [22] used different models of the analytic multi-criteria decision-making process, such as an analytical hierarchy process (AHP), weighted linear combination (WLC), and Boolean logic, to manage layers to establish specific databases for urban waste landfills site location. Their results indicated that AHP and WLC methods in the early stages had better decision-making powers for locating landfill sites when compared to Boolean logic. 
Table 2. Comparison of some MCDA methods.

\begin{tabular}{|c|c|c|c|}
\hline S/No & $\begin{array}{c}\text { MCDA } \\
\text { Methods }\end{array}$ & Advantages & Disadvantages \\
\hline 1 & AHP & $\begin{array}{l}\text { - it is easy to handle } \\
\text { complex conflicting } \\
\text { objectives in decision- } \\
\text { making process. } \\
\text { - It enables the } \\
\text { computation of } \\
\text { consistency ratio. } \\
\text { - It is straightforward } \\
\text { and simple to use by } \\
\text { using pairwise } \\
\text { comparison. }\end{array}$ & $\begin{array}{l}\text { - Subjective evaluation i.e. } \\
\text { conversion from verbal to } \\
\text { numeric scale. } \\
\text { - Limited to the use of 1-9 } \\
\text { scale. } \\
\text { - Very tedious in terms of } \\
\text { calculations of pairwise } \\
\text { comparison matrix, } \\
\text { normalization, and } \\
\text { consistency ratio. } \\
\text { - Inconsistent judgement by } \\
\text { decision makers }\end{array}$ \\
\hline 2 & WLC & $\begin{array}{l}\text {-It has distinct } \\
\text { advantages in } \\
\text { preference modeling, } \\
\text { weight elicitation, and } \\
\text { aggregation } \\
\text { performance. } \\
\text {-It can be applied both } \\
\text { in raster and vector } \\
\text { format. }\end{array}$ & $\begin{array}{l}\text {-Absence of unit of } \\
\text { measurement will lead to } \\
\text { error. }\end{array}$ \\
\hline 3 & $\begin{array}{l}\text { FUZZY } \\
\text { Logic }\end{array}$ & $\begin{array}{l}\text { - It is able to identify } \\
\text { and describe the } \\
\text { uncertainties related } \\
\text { with criteria } \\
\text { assessment. } \\
\text { - It enables criteria } \\
\text { weighting and } \\
\text { standardization. } \\
\text { - Ability to provide } \\
\text { sufficient mapping of } \\
\text { the decision-making } \\
\text { vagueness and } \\
\text { Imprecise knowledge. }\end{array}$ & $\begin{array}{l}\text { - Inconsistencies cannot be } \\
\text { processed in multiple criteria } \\
\text { decision problems such as } \\
\text { criteria ranking. }\end{array}$ \\
\hline
\end{tabular}

\section{Conclusions}

An attempt has been made to review the recent existing literature regarding GIS-based and MCDA application in landfill site selection process. From this paper, it has been proved that they are both efficient tools to be used in this type of site selection analysis. The main aim of the MCDA is to provide aid to the decision-makers in choosing the best candidate site from the variety possible choice alternatives under the presence of multiple priorities. Also, it has been noticed that from the previous decades, the integration of geospatial based strategies coupled with multi-criteria decision analysis has increased rapidly, this can be because of its accuracy, efficiency, and less time consuming compared to the conventional methods. Furthermore, the incorporation of the GIS-based technology and MCDA in landfill site selection and other land suitability analysis has been found useful and thus, aids in sustainable development. The study will help the waste management authorities and decision-makers to know which method is to be considered most effective when siting a new landfill. 


\section{References}

1. Z. G. Rahmat, M. V. Niri, N. Alavi, G. Goudarzi, A. A. Babae, Z. Baboli, M. Hosseinzadeh, KSCE J Civ Eng 21(1), 111-118 (2016)

2. A. Mornya, R. Majid, L. Yola, Identification of Landfill Sites by Using GIS and MultiCriteria Method in Batam, Indonesia, in 3rd International Graduate Conference on Engineering, Science and Humanities, University Tekologi Malaysia. amazonaws. com/academia. edu. (2010)

3. N. Alavi, G. Goudarzi, A. A. Babaei, N. Jaafarzadeh, M. Hosseinzadeh, Waste Manag Res 31(1), 98-105 (2013)

4. S. Z. Ahmad, S. M. S. Ahmad, H. Wan, Comparative site selection process based on different policies and guidelines for municipal solid waste landfill site, 10th International symposium \& exhibition on geoinformation 2011 (ISG 2011), Selangor, Malaysia, 27-29 September (2011)

5. M. Eskandari, M. Homaee, S. Mahmodi, Waste Manag 32(8), 1528-38 Aug (2012)

6. V. R. Sumathi, U. Natesan, and C. Sarkar, Waste Manag 28(11), 2146-60 Nov (2008)

7. A. Elahi and H. Samadyar, Middle East J Sci Res 22(9), 1294-1307 (2014)

8. B. Şener, M. L. Süzen, and V. Doyuran, Environ. Geol 49(3), 376-388 (2005)

9. O. B. Delgado, M. Mendoza, E. L. Granados, D. Geneletti, Waste manag 28, (7), 1137-1146 (2008).

10. M. Moeinaddini, N. Khorasani, A. Danehkar, A. A. Darvishsefat, M. Zienalyan, Waste Manag 30(5), 912-20 May (2010)

11. M. A. Alanbari, N. Al-Ansari, H. K. Jasim, Natural Sci 06(05), 282-304 (2014)

12. P. V. Gorsevski, K. R. Donevska, C. D. Mitrovski, J. P. Frizado, Waste Manag 32(2), 287-96, Feb (2012)

13. O. Demesouka, A. Vavatsikos, K. Anagnostopoulos, Waste Managt \& Res 32(4), 270296 (2014)

14. A. Beskese, H. H. Demir, H. K. Ozcan, H. E. Okten, Environ. Earth Sci 73, (7), 35133521 (2014)

15. M. Eskandari, M. Homaee, S. Mahmoodi, E. Pazira, M. T. Van Genuchten, Environ Sci Pollut Res Int 22(10), 7754-65 (2015)

16. N. B. Chang, G. Parvathinathan, J. B. Breeden, J Environ Manage 87(1), 139-53 (2008)

17. H. Voogd, Multicriteria evaluation for urban and regional planning. Pion London, (1983)

18. M. Doumpos and C. Zopounidis, "An overview of multiple criteria decision aid," in Multicriteria Analysis in Finance: Springer, 11-21 (2014)

19. D. Khan and S. R. Samadder, Waste Manag Res 32(11), 1049-62 (2014)

20. R. Al-Adamat, A. Diabat, G. Shatnawi, J. Arid Environ 74(11), 1471-1477 (2010)

21. J. Malczewski, Progress in planning 62(1), 3-65 (2004)

22. H. Shahabi, S. Keihanfard, B. B. Ahmad, M. J. T. Amiri, Environ. Earth Sci 71(9), 4221-4233 (2013)

23. T. L. Saaty, What is the analytic hierarchy process? in Mathematical models for decision support: Springer, 109-121, (1988)

24. J. Aerts, M. Van Herwijnen, R. Janssen, T. Stewart, J Environ Plann Man 48(1), 121$142(2005)$

25. T. Saaty, The analytic hierarchy and analytic network processes for the measurement of intangible criteria and for decision-making, Multiple criteria decision analysis: state of the art surveys, 345-405, (2005)

26. C. Makropoulos and D. Butler, Environ. Model. Softw. 21(1), 69-84 (2006). 
27. Trupti I. Lokhande, Sachin J. Mane, S. T. Mali, Int J Res in Eng, Sci and Tech 03 (2017)

28. S. P. Gbanie, P. B. Tengbe, J. S. Momoh, J. Medo, V. T. S. Kabba, Appl Geogr 36. 3$12(2013)$

29. A. A. Isalou, V. Zamani, B. Shahmoradi, H. Alizadeh, Environ. Earth Sci 68(6), 1745 1755 (2012) 